\title{
Natural killer T Cells: A Powerful Via in the Regulation of Non Communicable Chronic Diseases
}

\author{
Carlos Ramirez-Velazquez ${ }^{1, *}$, Juan Carlos Paredes-Palma ${ }^{2}$, Sandra Vanesa Patzi-Vargas ${ }^{3}$ \\ ${ }^{1}$ Allergy Service of the General Hospital "Fernando Quiroz Gutierrez", Institute of Security and Social Services of State Workers, Mexico \\ City, Mexico \\ ${ }^{2}$ Internal Medicine Service of the General Hospital "Fernando Quiroz Gutierrez", Institute of Security and Social Services of State Workers, \\ Mexico City, Mexico \\ ${ }^{3}$ Department of Biostatistics and Epidemiology, Center for Research and Continuing Education (CENINVEC), Nezahualcoyotl City, Mexico
}

Email address:

mustla@hotmail.com(C. Ramirez-Velazquez),ju.paredes@issste.gob.mx (J.C. Paredes-Palma),sv_savan@hotmail.com (S. V. Patzi-Vargas) ${ }^{*}$ Corresponding author

\section{To cite this article:}

Carlos Ramirez-Velazquez, Juan Carlos Paredes-Palma, Sandra Vanesa Patzi-Vargas. Natural killer T Cells: A Powerful Via in the Regulation of Non Communicable Chronic Diseases. Clinical Medicine Research. Special Issue: Globalization and Advances on Non-Communicable Chronic Diseases. Vol. 8, No. 6, 2019, pp. 137-143. doi: 10.11648/j.cmr.20190806.12

Received: October 13, 2019; Accepted: November 12, 2019; Published: December 17, 2019

\begin{abstract}
The Natural Killer T cells (NKT) constitute a population of T lymphocytes that co-express an antigen receptor (TCR) and a marker of natural killer cells (NK1.1). We have found that after stimulation through TCR, the NKT cells secrete various cytokines that play an important role in the innate immune response and have a fundamental participation in the initial stages of the immune response to many pathogens and tumours. NKT cells belong to a group of autoreactive $\mathrm{T}$ cells that are generated in the thymus, which is why they have been found to play an important role in the regulation of different autoimmune diseases, such as type 1 diabetes, systemic lupus erythematosus, multiple sclerosis, and others. Also, in adulthood there is an aging of the immune system known as immunosenescence, where a decrease and alteration of the function of NKT cells has been observed, which leads to a greater oncological, viral and autoimmune diseases. It has also recently been found that these cells participate in bronchial inflammation in patients with allergic asthma as well as in rhinitis and atopic dermatitis; having these cells a clear role in the regulation of various diseases and that has not been studied as a therapeutic target.
\end{abstract}

Keywords: Natural Killer T Cells, Autoimmune Diseases, Immune System Diseases

\section{Introduction}

Natural killer $\mathrm{T}$ cells (NKT) represent a group of lymphocytes that participate in an innate immune response. [1] The function of NKT cells has been extensively investigated in recent decades, they have a fundamental participation in the initial stages of immune response to many pathogens and tumours. NKT cells have also been implicated in the regulation of different autoimmune diseases, maintain immune privilege, and play an important role in the rejection of transplanted tissue [2-4].

The NKT cell antigen presentation system is through CD1 that belongs to a family of non-polymorphic molecules like Major Histocompatibility Complex (MHC) class I, presenting glycolipid antigens such as isoglobotrihexosylceramide (iGb3; a lysosomal glycolipid), phosphatidylcholine, and $\alpha$-galactosylceramide ( $\alpha$-GalCer; a synthetic sphingolipid) [5]. There are two groups of molecules based on similar sequences: group I (CD1a, CD1b, CD1c) that present both own and foreign glycolipid antigens (mycobacteria) to $\mathrm{T}$ cells and group II (CD1d) that presents own glycolipid antigens to NKT cells [6]. CD1d are expressed by all hematopoietic cells, including mature and immature T cells, B cells, dendritic cells and macrophages [7]. The presentation of glycolipid antigens by CD1d to NKT cells plays an important role in the synthesis and secretion of immunoregulatory cytokines.

NKT cells constitute a population of $\mathrm{T}$ lymphocytes that co-express an antigen receptor ( $\mathrm{T}$ cell receptor; TCR) and a marker of natural killer cells (NK1.1) [5]. They can be broadly divided according to the kind of TCR that is usually 
expressed, $\alpha \beta$ vs $\gamma \delta$ (the first ones with a greater predominance) [6]. NKT cells express different phenotypes on their surface and it varies according to the studied species. In mice, most NKT cells express an invariant TCR, consisting of the V $\alpha 14 \mathrm{~J} \alpha 281$ chain and a preferential use of the chains V $\beta 8.2$ (50\%), V $\beta 7$ (14\%), y V $\beta 2$ (7\%); they also express NK1.1 markers (CD161), Ly49, CD11a (LFA-1 $\alpha$ ), CD122, CD28+, CD69+, CD45RB+, chemokine receptors such as CCR2 and CCR6 (5). In humans they express the $\alpha$ homologue chain V $\alpha 24 \mathrm{~J} \alpha 18$ [8], as well as the chain V $\beta 11$, NKR-P1A (CD161), CD122, CD56, CD57 and other molecules such as CD44 high, CD45RB low, CD62L high, indicators of an activation/memory phenotype, and CD69, early activation marker, CD28+, CD49d/e/f, chemokine receptors such as CCR2, CCR5, CXCR3, CXCR4, CCR6, CXCR6 (Figure 1). In recent years, it has also been found the expression of the CRTAM molecule in both species, once they have been activated by mitogens $[5,9]$.

NKT cells can be classified according to the expression of the following markers: CD4-CD8- (double negative; DN), $\mathrm{CD} 4+$ in mice, in addition to these markers, in humans it has been found in a lower proportion $\operatorname{CD} 8 \alpha \alpha+$, and CD $8 \alpha \beta+[8]$.

In mice, NKT cells are located in sites traditionally occupied by $\mathrm{T}$ lymphocytes, often in the liver (30-50\%), bone marrow (20-30\%), thymus (0.3-0.5\%), spleen, lymph nodes $(0.3 \%)$, peripheral blood (4\%) and lungs $(7 \%)$. In humans, in peripheral blood $0.1-1 \%$ and liver $<0.5 \%$ [10].

It has been found that after stimulation through TCR, the NKT cells secrete IL-2, IL-4, IL-5, IL-10, IL-13, INF- $\gamma$, TNF- $\alpha$, GM-CSF, lymphotactin, macrophage inflammatory protein (MIP)-1 $\alpha$, MIP-1 $\beta$, y RANTES. This varies according to the co-expression of $\mathrm{CD} 4+, \mathrm{CD} 8+$ or $\mathrm{DN}$, as well as the state of maturation of NKT cells and the age of the host (in the umbilical cord of human neonates, it has been found that NKT cells preferentially secrete IL-4 and in old mice as in mature NKT cells secrete INF- $\gamma$ ) [6]. The activation of NKT cells requires signals through TCR and costimulatory molecules such as CD28, CTLA-4, CD80, CD86, CD40 and CD40 ligand (CD40L), contrary to Ly49 which is inversely expressed with the NKT cell activation.

In this article, we will mention the mechanisms by which NKT cells have been implicated in the regulation of the immune response and how they play a crucial role in the protection or development of various diseases. With age, it has been found an alteration in the functionality of these cells that promote the development of autoimmune diseases, cancer and viral infections. This entity is known as immunosenescence that will be briefly discussed in this article.

\section{Natural Killer T Cells and Autoimmunity}

NKT cells belong to a group of self-reactive $\mathrm{T}$ cells that originate in the thymus, play an important role in the regulation of different autoimmune diseases that have been studied in both animal and human models. In animal models, it has been determined that the activation of Vi NKT cells through GalCer prevent autoimmunity and inflammation [11].

In non-obese diabetic mice (NOD) that developed type 1 diabetes, progressive destruction of insulin-producing $\beta$ cells was found with mononuclear cell infiltration. In many studies, it has been identified an infiltration of Th1-type cytokine-producing cells that cause destructive insulitis [9, 12-14]. A decrease in the number of V14i NKT cells has been found in the NOD mice thymus, spleen, bone marrow and liver. An increase in the number of V14i NKT cells by transfer or induction inhibits the development or progression of type 1 diabetes [15-20]. A decrease in IL-4 production has been found after TCR stimulation of V14i NKT in NOD mice [21-22]. In many studies, it has been found that the Th2 response of V14i NKT cells, especially IL-4 and/or IL-10, were important cytokines that are considered protective for the development of this disease [20]. A decrease in V24+ CD4- CD8- (double negative-DN) cells in peripheral blood has been reported in humans with type 1 diabetes, compared to twins and triplets without diabetes. Our working group demonstrated that the CRTAM molecule favours the production of IFN- in peripheral blood invariant NKT (iNKT) cells of patients with type 1 diabetes [9]. There is also an alteration in the production of IL- 4 by V24 NKT cells as in NOD mice [23].

A decrease in V14 NKT cells has also been found in other autoimmune diseases in experimental models in mice, such as experimental autoimmune encephalomyelitis (EAE) and systemic lupus erythematosus (SLE). In mice with EAE that present an alteration in the production of IL-4 by V14 NKT cells, when stimulated with GalCer favours a Th1 response, this same stimulus without alterations in IL-4 favours a Th2 response that is protective for these diseases [24-28].

In humans with the presence of SLE as well as scleroderma, it has also been found a decrease in the number of V24V11+ NKT cells in peripheral blood compared to healthy patients [29]. Some studies have reported an increase in $+\mathrm{DN}$ cells in peripheral blood in patients with scleroderma and SLE, it has been proposed in these patients that other $\mathrm{T}$ cells with different rearrangements other than $\mathrm{V} \alpha 24$ for CRT may be self-aggressive compared to cells with invariant $\mathrm{V} \alpha 24 \mathrm{~J} \alpha \mathrm{Q}$ that function as regulatory cells [30].

In patients with multiple sclerosis (MS) there is a decrease in $\mathrm{V} \alpha 24 \mathrm{~J} \alpha \mathrm{Q}+$ cells in peripheral blood compared to control patients, a decrease in the production of IL- 4 by these cells has also been found. These alterations have not been found in other autoimmune diseases of the nervous system. Interestingly, MS cells with Vo24JQ TCR that are rarely present have been searched for in MS lesions, but these cells have been found more frequently in chronic inflammatory lesions of demyelinating polyneuropathy [31-33].

Patients with rheumatoid arthritis also have a decrease of NKT cells in peripheral blood [34]. It has been found an increase in V $\alpha 24+\mathrm{DN}$ cells in the synovial fluid. As in scleroderma, these cells present TCR rearrangements other 
than $\mathrm{V} \alpha 24 \mathrm{~J} \alpha \mathrm{Q}$ that present greater self-aggression [35].

In experimental models, a potent route of treatment in autoimmune disease has been found through NKT cells, this can be achieved by transferring NKT cells to NOD mice which prevent the development of type 1 diabetes. Stimulation of NKT cells with $\alpha$-GalCer can be an important therapeutic strategy. In NOD mice this treatment prolongs the survival of pancreatic islets. In humans, administration of $\alpha$ GalCer has toxic effects, causes liver damage and when administered in old mice causes an increase in NKT cells that causes death [36]. In other studies, the administration of $\alpha$ GalCer has been carried out in association with IL-7 that favours a $\mathrm{Th} 2$ response but is still in experimental stages.

\section{MOUSE}

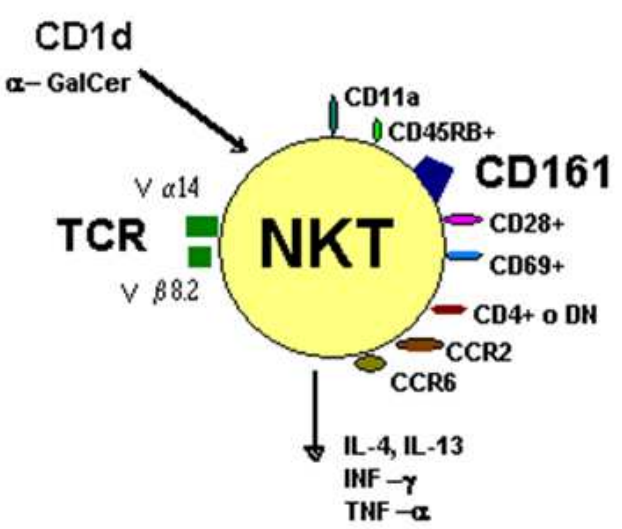

\section{HUMAN}

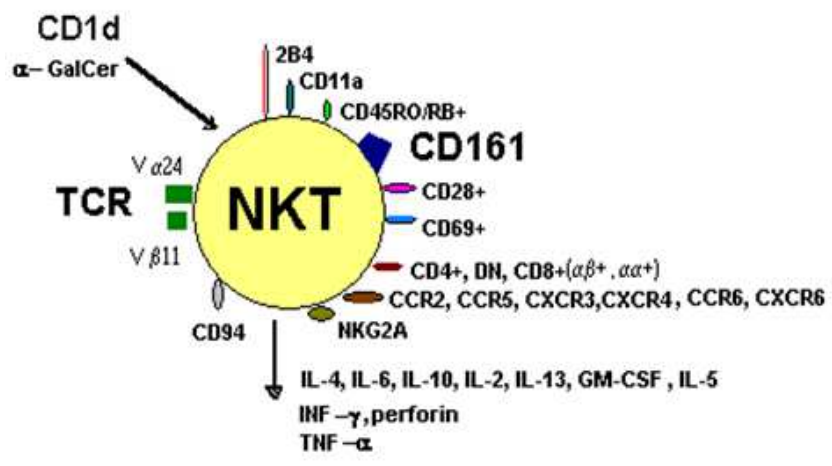

Figure 1. Comparison of NKT cells between mouse and humans Va14 / NKT cells have not shown any difference in cytokine secretion, nor have chemokine receptor expression been extensively characterized. The type of cytokines that secrete Va24 / NKT cells depend on the expression of CD4 +, $C D 8+, D N$ (double negative).

It should be noted that patients suffering from various autoimmune diseases, the use of drugs with immunosuppression effects is well indicated, such as prednisolone, methrotexate, cyclosporine, etc. These drugs have effects on the number and functionality of NKT cells, so the levels should be measured routinely and the functionality of these cells should be evaluated in these patients since they play a very important role in the regulation in the autoimmunity.

\section{Natural Killer T Cells and Immunosenescence}

Immunosenescence is referred to as the state where there is a decrease in both the number and the function of the cells involved in the immune response, this alteration is associated with aging of animals and humans [37]. It has been observed that $\mathrm{T}$ cells are more dramatically affected with age, although there is also evidence of alterations in the number, phenotype and function of other age-related immune system cells. Among the cells affected in immunosenescence are NKT cells, which, as mentioned above, have an important function in the mechanisms of innate immune response [38].

In older mice, a decrease has been found mainly in $\mathrm{V} \alpha 14 \mathrm{i}$ NKT cells that express a $\alpha \beta T C R$. It has also been found a decrease in the production of INFy in these cells both at baseline and after stimulation with IL-12 [39], as well as a reduction in the number of perforin granules, which favours a poor cytotoxic response. These alterations of $\mathrm{V} \alpha 14 \mathrm{i}$ NKT cells of mice associated with age have also been found in human V $\alpha 24 i$ NKT cells. The decrease in the production of INF causes alterations in the activation of NK cells, which leads to a decrease in the production of cytokines involved in the innate immune response (IL-12 and INF $\alpha / \beta$ ) against bacterial and viral infections [40]. The decrease in number and alteration of function of the NKT cells observed in aging contribute to the deterioration of the immune response, which could favour the emergence of several diseases related to aging such as infections, tumours and autoimmune diseases [41].

Maturation and differentiation of NKT cells are mainly carried out in the thymus, although these functions have also been found in extrathymic organs such as the liver [42]. There is clear evidence that demonstrates the finding of pluripotential stem cells with a c-kit marker in the liver, which originates several cell lines involved in the immune response, such as NKT cells [43]. This ability to originate, as well as to favour the maturation and differentiation of NKT cells by the liver, has a primary role in the compensatory mechanisms that are carried out in old age [42].

NKT cells that express a $\gamma \delta$ TCR are referred to as "nonclassical" because they are not restricted to CD1d, these cells express NK1.1, do not express CD4+ or $\mathrm{CD} 8+$, are double negative. After stimulation with IL-12, these cells contribute to the production of INF $\gamma$ but not IL-4 [40]. NKT cells that express $\gamma \delta$ TCR are found mainly in the liver and represent 2 $4 \%$ of the total NKT cells. These cells are increased at birth, having a primary role in the protection of the host in early stages of life until the appearance of NKT cells expressing $\alpha \beta T C R$ [44] The NKT cells that express a $\gamma \delta$ TCR are preserved in elder humans, because it presents activation of the CD69 marker and there is no activation of apoptosis via Fas [45]. These cells show an increase in the production of INF $\gamma$ as well as the cytotoxic response, these changes observed in NKT cells that express $\gamma \delta$ TCR plays an important role in compensatory mechanisms in senescence [46]. 
NKT cells play a fundamental role in the regulation of the immune response, the alterations observed in immunosenescence are an important factor in the appearance of several classic diseases in adulthood.

\section{Natural Killer T Cells and Allergy}

It is well known that allergic diseases are caused by an increase in the expression of Th2 response of CD4+ T lymphocytes and other alterations and variations of the immune system upon contact with allergens, with a prior individual genetic predisposition. In the mechanism described during the first minutes of the initial contact with the allergen, the sensitized IgE mast cells stimulates degranulation, releasing preformed mediators such as histamine, leukotrienes, chemokines and cytokines, which favour the presence of hyperreactivity, remodelling and damage of the airways [47].

NKT cells are involved in some diseases related to autoimmunity, cancer and recently in allergic diseases (asthma, allergic rhinitis and atopic dermatitis) and are closely related to allergen tolerance mechanisms [48, 49]. Recent studies have found the presence of iNKT cells with a predominance of $\mathrm{CD} 4+$ expression in bronchioalveolar lavages as well as lung biopsies of asthmatic patients (8) and NKT cells have also been found in the sputum of asthmatic patients with different degrees of severity [50].

When CD4+ Th2 T lymphocytes are activated they secrete interleukins such as IL-4, IL-5, IL-9 and IL-13, conditioning an inflammatory state characteristic of allergic diseases; and when predominantly CD4+ iNKT cells are activated through CD1d, they produce IL4 and IL13, similar to the mechanisms described with CD4+ Th2 T lymphocytes [51]. The iNKT cells play an important role in the development of bronchial hyperreactivity (BHR), in some animal studies, it has been found that these cells alone are capable of developing BHR [52]. The presence of iNKT cells is related to the severity of asthma, it has also been found that the presence of these cells accounts for approximately $10-30 \%$ of patients with asthma who respond poorly to corticosteroid therapy $[53,54]$.

The iNKT cells are activated through glycolipid antigens presented by CD1d, some pollens (cypress) have lipid characteristics that can promote the expression of IL-4 and IL-13 by the iNKT cells, conditioning BHR [55]. Finding abundant NKT cells in lungs of patients represent a higher risk of developing the disease and it is believed that destroying them and interfering with their activation allows the prevention of asthma [56-58]. Within the different mechanisms apparently involved in Asthma development are TSLP, IL25, TNF $\alpha$, oxidative stress and NKT cells that play an important role in the development of asthmatic symptoms, strongly indicating that these NKT cells are required for the presence of asthma [47].

It is important to mention that there are 3 types of NKT cells: Type I (referred to as classic or NKT invariant cells) are those that express an invariant $\alpha \beta T C R$ (preserved), expressed by the V $\alpha 14-\mathrm{J} \alpha 18$ gene in mice and Va24-J $\alpha 18$ in humans, restricted to CD1d; Type II (non-classical or noninvariant NKT cells) do not have an invariant TCR, but are restricted to CD1d; Type III does not have an invariant TCR nor are they restricted by CD1d, they are restricted by MHCI and MHC-II. Type II and type III NKT cells have also been implicated in patients with asthma but have been poorly studied [59-62].

Recent studies have found evidence of CCR9 expression on iNKT cells in peripheral blood as well as in biopsy samples of patients with asthma. The iNKT cells exhibit expression of CCR9 which is stimulated by CCL25 of dendritic cells (and probably epithelial cells), which conditions phosphorylation of CD226, which results in $\mathrm{T} \alpha \beta$ CD3+ cells being able to target Th2 type response [63, 64]. (Figure 2)

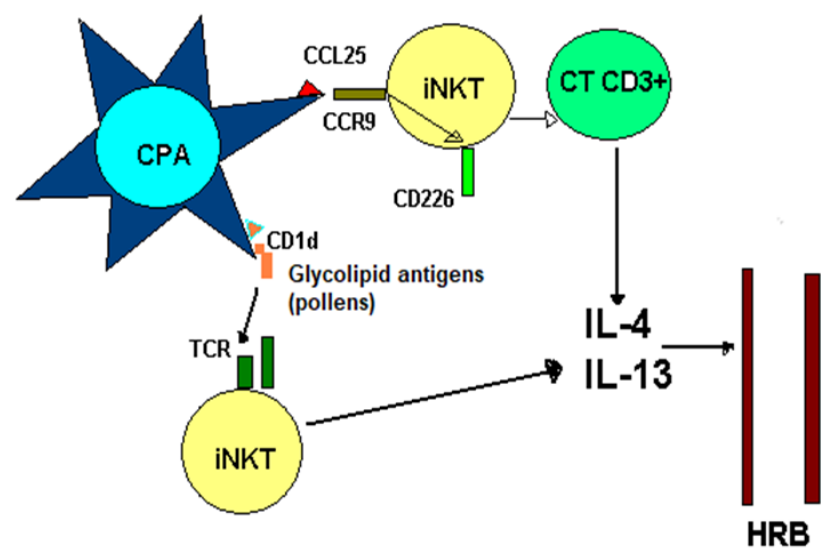

Figure 2. The pathways involved in the synthesis of $I L-4$ and $I L-13$ by invariant NKT cells. The iNKT cells are activated through the antigenic presentation of exogenous glycolipids (pollens) through CDld, which favours the expression of IL-4 and IL-13, which leads to an inflammatory state in allergic conditions, similar to CD4 + Th2 T cell response. The expression of IL4 and IL-13 is also favoured by the stimulation of the CCR9 chemokine receptor of the iNKT cells by means of the interaction with CCL25 of the dendritic cells, which favours the phosphorylation of the CD226 of the iNKT cells, which causes a Th2 type response in CD3 $+T$ cells. iNKT: invariant natural killer cells. CD3 +CT: CD3 + T cells. IL-4: interleukin-4. IL-13: interleukin-13. HRB: bronchial hyperreactivity.

We consider this information important since most of the recent studies that lay the foundations concerning the presence of these mechanisms have been performed in mice and few in humans, specifically in the relationship of NKT cells and allergy. This is important since it lays the basis for understanding the immunopathological mechanisms for the clinical expression of allergic diseases and asthma since previously they were believed to be mediated only by Th2 cells. However, this activation and regulation may be carried out in a direct or indirect way through NKT cells.

\section{Conclusion}

Recently it has been found that NKT cells constitute a population of $\mathrm{T}$ lymphocytes that participate in the innate immune response and play an important role in the initial stages of the immune response to many pathogens and 
tumours. Also, there is multiple evidence of the participation of NKT cells in the regulation of various immunological diseases such as allergic and autoimmune diseases. These observations are reinforced when these cells decrease in adulthood known as immunosenecence, conditioning major autoimmune, infectious and tumour problems. These cells should be studied as a therapeutic target and assess their clinical utility in various diseases where they are involved.

\section{Conflict of Interest}

The author reports no conflicts of interest in this work.

\section{Acknowledgements}

The English Language Editing of this study was funded for Centro de Investigación y Educación Continua, S. C. CENINVEC.

\section{References}

[1] Bendelac A, Bonneville M, Kearney JF. Autorreactivity by desing: innate $\mathrm{B}$ and $\mathrm{T}$ lymphocytes. Nature Rev Immunol 2001; 1 (3): 177-86.

[2] Torina A, Guggino G, La Manna MP, Sireci G. The Janus Face of NKT Cell Function in Autoimmunity and Infectious Diseases. Int J Mol Sci. 2018; 19 (2): 1-10.

[3] Krijgsman D, Hokland M, Kuppen PJK. The Role of Natural Killer $\mathrm{T}$ Cells in Cancer-A Phenotypical and Functional Approach. Front Immunol 2018; 9 (367): 1-21.

[4] Sonoda KH, Exley M, Snapper S, Balk SP, Stein-Streilein J. Cd1- reactive natural killer $T$ cells are required for development of systemic tolerance through an immuneprivileged site. J Exp med 1999; 190 (9): 1215-26.

[5] Patiño-Lopez G, Hevezi P, Lee J, Willhite D, Verge GM, Lechner SM, et al. Human class-I restricted T cell associated molecule is highly expressed in the cerebellum and is a marker for activated NKT and CD8+ T lymphocytes. J Neuroimmunology 2006; 171 (1-2): 145-55.

[6] Aleksandar KS, Jang JP, Joyce S. Innate self recognition by an invariant, rearreged $\mathrm{T}$ cell receptor and its immune consequences. Immunology 2003; 109 (2): 171-84.

[7] Godfrey DI, Hammond KJ, Poulton LD, Smyth MJ, Baxter AG. NKT cells: facts, functions and fallacies. Immunol Today 2000; 21 (11): 573-83.

[8] Akbari O, Faul JL, Hoyte EG, Berry GJ, Wahlström J, Kronenberg M, et al. CD4+ invariant T-cell-receptor+ natural killer T cell in bronchial asthma. N Engl Med 2006; 354 (11): 1117-29.

[9] Beristain-Covarrubias N, Canche-Pool EB, RamirezVelazquez C, Barragan-Galvez JC, Gomez-Diaz RA, OrtizNavarrete V. Class I-Restricted T Cell-Associated Molecule Is a Marker for IFN- $\gamma$-Producing iNKT Cells in Healthy Subjects and Patients with Type 1 Diabetes. J Interferon Cytokine Res 2017; 37 (1): 39-49.

[10] Hammond KJ, Godfrey DI. NKT cells: potential targets for autoimmune disease therapy? Tissue Antigens 2002; 59 (5): 353-63.

[11] Godfrey D. I, Kronenberg M. Going both ways: immune regulation via CD1d-dependent NKT cells. J. Clin. Invest. 2004; 114 (10): 1379-1388.

[12] Baxter AG, Kinder SJ, Hammond KJL, Scollay R, Godfrey DI. Association Between $\alpha \beta T C R+$ CD4-CD8-T-Cell deficiency and IDDM in NOD/Lt mice. Diabetes 1997; 46 (4): $572-82$.

[13] Godfrey DI, Kinder SJ, Silvera P, Baxter AG. Flow cytometric study of T cell development in NOD mice reveals a deficiency in TCR+ CD4-CD8- thymocytes. J Autoimmunity 1997; 10 (3): $279-85$.

[14] Gombert JM, Herbelin A, Tancredebohin E, Dy M, Carnaud C, Bach JF. Early quantitative and functional deficiency of NK1+ -like thymocytes in the NOD mouse. Eur J Immunol 1996; 26 (12): 2989-98.

[15] Hammond KJ, Pellicci DG, Poulton LD, Naidenko OV, Scalzo AA, Baxter AG, et al. CD1d- resticted NKT cells: an interstrain comparison. J Immunol 2001; 167 (3): 1164-1173.

[16] Poulton LD, Smyth MJ, Hawke CG, Silvera P, Shepherd D, Naidenko OV, et al. Cytometric and functional analyses of NK and NKT cell deficiencies in NOD mice. Int Immunol 2001; 13 (7): 887-896.

[17] Hong S, Wilson MT, Serizawa I, Wu L, Singh N, Naidenko $\mathrm{OV}$, et al. The natural killer T-cell ligand -galactosylceramide prevents autoimmune diabetes in non-obese diabetic mice. Nat Med 2001; 7 (9): 1052-1056.

[18] Matsuki N, Stanic AK, Embers ME, Van Kaer L, Morel L, Joyce S. Genetic dissection of V $\alpha 14 \mathrm{~J} \alpha 18$ natural $\mathrm{T}$ cell number and funtion in autoimmune-prone mice. J Immunol 2003; 170 (11): 5429-5437.

[19] Lehuen A, Lantz O, Beaudoin L, Laloux V, Carnaud C, Bendelac A, et al. Overexpression of natural killer $\mathrm{T}$ cells protects Va14-Ja281 transgenic nonobese diabetic mice against diabetes. J Exp Med 1998; 188 (10): 1831-1839.

[20] Hammond KJL, Poulton LD, Palmisano LJ, Silveira PA, Godfrey DI, Baxter AG. -T cell receptor (TCR)+ CD4- CD8(NKT) thymocytes prevent insulin-dependent diabetes mellitus in nonobese diabetic (NOD)/Lt mice by the influence of interleukin (IL)-4 and/or IL-10. J Exp Med 1998; 187 (7): 1047-1056.

[21] Wang B, Geng YB, Wang CR. CD1-restricted NKT cells protect nonobese diabetic mice from developing diabetes. J Exp Med 2001; 194 (3): 313-320.

[22] Sharif S, Arreaza GA, Zucker P, Mi Qs, Sondhi J, Naidenko $\mathrm{OV}$, et al. Activation of natural killer $\mathrm{T}$ cells by galactosylceramide treatment prevents the onset and recurrence of autoimmune type 1 diabetes. Nat Med 2001; 7 (9): 1057-1062.

[23] Wilson SB, Kent SC, Horton HF, Hill AA, Bollyky PL, Hafler $\mathrm{DA}$, et al. Multiple differences in gene expression in regulatory V 24J Q T cells from identical twins discordant for type 1 diabetes. Proc Natl Acad Sci USA 2000; 97 (13): 7411-7416.

[24] Owens T, Wekerle H, Antel J. Genetic models for CNS inflammation. Nat Med 2001; 7 (2): 161-6. 
[25] Pal E, Tabira T, Kawano T, Taniguchi M, Miyake S, Yamamura T. Costimulation dependent modulation of experimental autoimmune encephalomyelitis by ligand stimulation of Va14 NK T cells. J Immunol 2001; 166 (1): $662-8$.

[26] Miyamoto K, Miyake S, Yamamura T. Asynthetic glycolipid prevents autoimmune encephalomyelitis by inducing TH2 bias of natural killer T cells. Nature 2001; 413 (6855): 531-4.

[27] Singh AK, Wilson MT, Hong S, Olivares-Villagómez D, Du C, Stanic AK, et al. Natural killer T cell activation protects mice against experimental autoimmune encephalomyelitis. J Exp Med 2001; 194 (12): 1801-11.

[28] Jahng AW, Maricic I, Pedersen B, Burdin N, Naidenko O, Kronenberg $\mathrm{M}$, et al. Activation of natural killer $\mathrm{T}$ cells potentiates or prevents experimental autoimmune encephalomyelitis. J Exp Med 2001; 194 (12): 1789-99.

[29] Kojo S, Adachi Y, Keino H, Taniguchi M, Sumida T. Dysfunction of T cell receptor AV24AJ18+, BV11+ doublenegative regulatory natural killer $\mathrm{T}$ cells in autoimmune diseases. Arthritis Rheum 2001; 44 (5): 1127-38.

[30] Sumida T, Sakamoto A, Murata H, Makino Y, Takahashi H, Yoshida S, et al. Selective reduction of $\mathrm{T}$ cells bearing invariant $\mathrm{Va} 24 \mathrm{JaQ}$ antigen receptor in patients with systemic sclerosis. J Exp Med1995; 182 (4): 1163-8.

[31] van der Vliet HJ, von Blomberg BM, Nishi N, Reijm M, Voskuyl AE, van Bodegraven AA, et al. Circulating Va24+ $\mathrm{V} \beta 11+\mathrm{NKT}$ cell numbers are decreased in a wide variety of diseases that are characterized by autoreactive tissue damage. Clin Immunol 2001; 100 (2): 144-8.

[32] Illes Z, Kondo T, Newcombe J, Oka N, Tabira T, Yamamura T. Differential expression of NK T cell V24JQ invariant TCR chain in the lesions of multiple sclerosis and chronic inflammatory demyelinating poly neuropathy. J Immunol 2000; 164 (8): 4375-81.

[33] Gausling R, Trollmo C, Hafler DA. Decreases in interleukin-4 secretion by invariant CD4-CD8-V24JQ T cells in peripheral blood of patients with relapsing-remitting multiple sclerosis. Clin Immunol 2001; 98 (1): 11-7.

[34] Yanagihara Y, Shiozawa K, Takai M, Kyogoku M, Shiozawa S. Natural killer (NK) T cells are significantly decreased in the peripheral blood of patients with rheumatoid arthritis (RA). Clin Exp Immunol 1999; 118 (1): 131-6.

[35] Maeda T, Keino H, Asahara H, Taniguchi M, Nishioka K, Sumida T. Decreased TCR AV24AJ18+ double-negative T cells in rheumatoid synovium. Rheumatology (Oxford) 1999; 38 (2): $186-8$.

[36] Osman Y, Kawamura T, Naito T, Takeda K, Van Kaer L, Okumura K, et al. Activation of hepatic NKT cells and subsequent liver injury following administration of alphagalactosylceramide. Eur J Immunol 2000; 30 (7): 1919-28.

[37] Pawelec G, Effros RB, Carusco C, Remarque E, et al. T cells and aging (update february 1999) Front Biosci. 1999; 4: 216-69.

[38] Pawelec G, Solana R, Remarque E, Mariani E. Impact of aging on innate immunity. J Leukoc Biol. 1998; 64 (6): 703-12.

[39] Mocchegiani E, Giacconi R, Muti E, Muzzioli M, Cipriano C. Plasticity of neuroendocrine-thymus interactions during ontogeny and ageing: role of zinc and arginine. Ageing Res
Rev. 2006; 5 (3): 281-309.

[40] Emoto M, Kaufmann SH. Liver NKT cells: an account of heterogeneity. Trends Immunol 2003; 24 (7): 364-69.

[41] DelaRosa O, Tarazona R, Casado JG, Alonso C, Ostos B, Peña J, et al. V 24+ NKT cells are decreased in elderly humans. Experimental Gerontology 2002; 37 (2): 213-17.

[42] Abo T, Kawamura T, Watanabe H. Physiological responses of extrathymic T cells in the liver. Immunol 2000; 174: 135-49.

[43] Watanabe H, Miyaji C, Seki S, Abo T. c-kit+ stem cells and thymocyte precursors in the livers of adult mice. J. Exp. Med. 1996; 184 (2): 687-93.

[44] Emoto M, Miyamoto M, Emoto Y, Zerrahn J, Kaufmann SH. A critical role of $\mathrm{T}$-cell receptor gamma/delta cells in antibacterial protection in mice early in life. Hepatology. 2001; 33 (4): 887-93.

[45] Colonna-Romano G, Potestio M, Aquino A, Candore G, Lio D, Caruso C. Gamma/delta T lymphocytes are affected in the elderly. Exp. Gerontol. 2002; 37 (2-3): 205-11.

[46] Mocchegiani E, Giacconi R, Cipriano C, Gasparini N, Bernardini $G$, Malavolta $M$, et al. The variations during the circadian cycle of liver CD1d unrestricted NK1.1+TCR $\gamma \delta+$ cells lead to successful aging. Role of metallothioneins/IL6/gp130/PARP-1 interplay in very old mice. Exp. Gerontol. 2004; 39 (5): 775-88.

[47] Umetsu DT, Dekruyff RH. Immune dysregulation in asthma. Current Opinion in Immunology 2006; 18 (6): 727-732.

[48] Elkhal A, Pichavant M, He R, Scott J, Meyer E, Goya S, et al. $\mathrm{CD} 1 \mathrm{~d}$ restricted natural killer $\mathrm{T}$ cells are not required for allergic skin inflammation. J Allergy Clin Immunol 2006; 118 (6): 1363-8.

[49] Ronger-Savle S, Valladeau J, Claudy A, Schmitt D, PeguetNavarro J, Dezutter-Dambuyant C, et al. TGF Inhibits CD1d Expression on Dendritic Cells. J Invest Dermatol 2005; 124 (1): 116-118.

[50] Hamzaoui A, Cheik Rouhou S, Graïri H, Abid H, Ammar J, Chelbi H, et al. NKT cells in the induced sputum of severe asthmatics. Mediators of Inflammation 2006; 2006 (2): 71214.

[51] Umetsu DT, De Kruyff RH. A role for natural killer T cells in asthma. Nature Reviews Immunology 2006; 6 (12): 953-958.

[52] Amano M, Baumgarth N, Dick MD, Brossay L, Kronenberg M, Herzenberg LA, et al. CD1 expression defines subsets of follicular and marginal zone B cells in the spleen: $\beta 2-$ microglobulin-dependent and independent forms. J. Immunol. 1998; 161 (4): 1710-1717.

[53] Adcock IM, Ito K. Steroid resistance in asthma: a major problem requiring novel solutions or a nonissue? Curr. Opin. Pharmacol. 2004; 4 (3): 257-262.

[54] Ito K, Chung KF, Adcock IM. Update on glucocorticoid action and resistance. J. Allergy Clin. Immunol. 2006; 117 (3): 522-543.

[55] Agea E, Russano A, Bistoni O, Mannucci R, Nicoletti I, Corazzi L, et al. Human CD1-restricted T cell recognition of lipids from pollens. J. Exp. Med. 2005; 202 (2): 295-308.

[56] Berry MA, Hargadon B, Shelley M, Parker D, Shaw DE, Green $\mathrm{RH}$, et al. Evidence of a role of tumor necrosis factor alpha in refractory asthma. N Engl J Med. 2006; 354 (7): 697-708. 
[57] Akbari O, Stock P, Meyer E, Kronenberg M, Sidobre S, Nakayama T, et al. Essential role of NKT cells producing IL4 and IL13 in the development of allergen-induced airway hyperreactivity. Nat Med. 2003; 9 (5): 582-588.

[58] Bahceciler NN, Arikan C, Taylor A, Akdis M, Blazer k, Barlan IB, et al. Impact of sublingual immunotherapy on specific antibody levels in asthmatic children allergic to house dust mites. Int Arch Allergy Immunol. 2005; 136 (3): 287-294.

[59] Godfrey DI, Kronenberg M. Going both ways: Immune regulation via CD1d-dependent NKT cells. J. Clin. Invest. 2004; 114 (10): 1379-1388.

[60] Taniguchi M, Harada M, Kojo S, Nakayama T, Wakao H. The regulatory role of $\mathrm{V} \alpha 14$ NKT cells in innate and acquired immune response. Annu. Rev. Immunol. 2003; 21: 483-513.
[61] Exley MA, Koziel MJ. To be or not to be NKT: natural killer $\mathrm{T}$ cells in the liver. Hepatoloy 2004; 40 (5): 1033-1040.

[62] Seino K, Taniguchi M. Functionally distinct NKT cell subsets and subtypes. J. Exp. Med. 2005; 202 (12): 1623-1626.

[63] Kay AB. Natural Killer T Cells and Asthma. N Engl J Med. 2006; 354 (11): 1186-1188.

[64] Carpio-Pedroza JC, Vaughan G, del Rio-Navarro BE, del RíoChivardí JM, Vergara-Castañeda A, Jiménez-Zamudio LA, et al. Participation of CD161 (+) and invariant natural killer T cells in pediatric asthma exacerbations. Allergy Asthma Proc. 2013; 34 (1): 84-92. 